\title{
Engineering Students' Performances in Mathematics through Project-based Learning
}

\author{
N. Razali ${ }^{1, *}$, N. A. Zainuri ${ }^{1}$, H. Othman ${ }^{1}$, Z. M. Nopiah ${ }^{1}$, N. A. A. Bakar ${ }^{2}$ \\ ${ }^{1}$ Department of Engineering Education, Faculty of Engineering and Built Environment, Universiti Kebangsaan Malaysia, Malaysia \\ ${ }^{2}$ Institut Matematik Kejuruteraan, Universiti Malaysia Perlis, Malaysia
}

Received February 13, 2020; Revised April 1, 2020; Accepted April 19, 2020

Copyright $\mathrm{C} 2020$ by authors, all rights reserved. Authors agree that this article remains permanently open access under the terms of the Creative Commons Attribution License 4.0 International License

\begin{abstract}
Project-based learning is an example of active learning and is student-driven, interdisciplinary, collaborative and technology-based. To test the hypothesis that project-based learning maximises course performance, we analysed a difficulty index of examination scores or failure rates and compared between 422 students in the 2016/2017 session, who took the Vector Calculus course and project-based learning with 342 students from the 2015/2016 session without project-based learning. The analysis of the difficulty index is used to investigate the achievement of the course outcome and the analysis on the correlation between the project-based learning scores and the final exam scores are identified using Pearson's product-moment correlation. The effect sizes indicate that on average examination scores improved by about $12 \%$ with project-based learning and students in classes with project-based learning were 3.4 times more likely to get as than students in classes without project-based learning. It is observed that the difficulty index for all course outcomes are achieved and distributed between a good range of $0.3-$ 0.8 . It is also proven that the students find it easier to answer the exam questions after the project-based learning is implemented based on the results of their mid and final semester exams.
\end{abstract}

Keywords Project-based Learning, Engineering Mathematics, Difficulty Index

\section{Introduction}

Engineers are increasingly being challenged and confronted with various situations in their profession that require them to think critically, creatively, and outside the box. Apart from meeting the needs of clients, the government, the environment, and the general public, an engineer at the same time has to be smart in consolidating the humanity in the course of employment (Deutsch, 2020; Li et al., 2020). The rapid development of technology and changes in organisational infrastructure are among the challenges that engineers nowadays have to face, hence they are required to have good generic skills such as communication and teamwork skills in complement their disciplinary expertise (Mills \& Treagust, 2003; Harpe et al., 2000; Male, 2010). In this scenario, institutions of higher learning play their roles in producing quality engineers with a broad perspective of their field of work. In line with the government's desire to produce more graduates in this field, science, technology, engineering, and mathematics education need to be strengthened in today's teaching and learning process (Bybee, 2010, Han et al., 2012).

To ensure these goals are achieved, institutions of higher education should take steps by changing and innovating their approach in teaching and learning. The Learning Pyramid illustrated by Rate (2010) shows that passive learning, such as attending lectures, reading, audio visual, and demonstration, is seen to have less effect on teaching and learning outcomes compared to active learning, in which students are directly involved in the process. In active learning, for example through group discussions, by conducting training and by teaching their own friends, students were more intrinsically motivated and had higher conceptual learning (Lalley \& Miller, 2007; Wood, 2004; Benware \& Deci, 1984). The outcome is different if the student is actively engaged in any learning methods used, either active or passive. The teaching and learning paradigm of 'what has been taught?' should be shifted to 'what has been learnt'? The lecturers should be the facilitators and co-constructors of knowledge in the process of developing student minds while the students themselves direct their own learning.

Project-based learning is an example of active learning and is a current instructional strategy that is student-driven, interdisciplinary, collaborative and technology-based (Wurdinger et al., 2020). Similar to cooperative learning 
where the learning process is student-centric (Saad, A., 2020), the students have to work in groups to solve challenging problems based on the curriculum. They have to gather information from variety of sources and synthesise, analyse and derive knowledge from them. This process is able to develop teamwork skills, information analysis skills, skills to teach friends, decision-making skills from data analysis and reflection skills on the ongoing learning process (Krajcik \& Blumenfeld, 2006; Carlson \& Sullivan, 1999). Adderly (1975) defined project-based learning as follows:

1. Involves the solution of a problem; often, though not necessarily, set by the student himself/herself.

2. Involves initiative by the student or group of students, and necessitates a variety of educational activities.

3. Commonly results in an end product (e.g. thesis, report, design plans, computer programme, and model).

4. Work often goes on for a considerable length of time.

5. Teaching staff are involved in an advisory, rather than authoritarian, role at any or all of the stages initiation, conduct, and conclusion.

Aspect (3) is crucial and distinguishes project-based learning and problem-based learning (Mills \& Treagust, 2003). Three general models of project work for educational purposes are listed below:

1. Project Exercise: Students should apply knowledge and techniques already acquired to an academic issue in a subject area already familiar to them. This represents the most traditional kind of project-based learning.

2. Project Component: Related to real world issues, interdisciplinary in nature and has a broader and larger scope. Develops problem-solving abilities and a capacity for independent work. Often, traditionally taught courses are studied in parallel with the project course.

3. Project Orientation: Denotes the entire curriculum philosophy of a programme of study; the project that students complete from the entire basis of their university education, while instructional teaching is provided only to supplement the requirement of the project topics.

Project exercise is the capstone event designed to integrate the subject material learnt during a specific course and is typically a teacher-centred project. This type of project-based learning is typically conducted during the final year of study. In contrast, project component and project orientation tend to leave more scope for student-centredness. In promoting active learning in higher education, the Department of Engineering Education (DEEd), took initiative by implementing project-based learning, specifically the project component model, as one of the teaching and learning methods in the Engineering
Mathematics 1 course (Vector Calculus) for the 2016/2017 academic session. This course is the first mathematics course that engineering students in the Faculty of Engineering and Built Environment, Universiti Kebangsaan Malaysia has to take. Based on previous research, it is observed that students find it difficult to understand engineering mathematics courses and the failure rate is high (Tang, Voon \& Julaihi, 2009; Othman et al., 2012). The purpose of this study is to investigate the course outcome achievement and the performance of the students in terms of their ability to answer the exam questions before and after the implementation of project-based learning.

\section{Methodology}

A total of 422 students in session 2016/2017 who took the Vector Calculus course were involved in this study and 342 students from session 2015/2016 were used as control items in determining the effectiveness of the project in overall performance. All students are from four different departments i.e. the department of civil engineering, the department of mechanical and structural engineering, the department of chemical and process engineering and the department of electric and electrical engineering. There are one lecturer and one tutor involved for each department in teaching this course making a total of 4 lecturers and 4 tutors for each session. The method of measurement was carried out by:

i) Measuring the difficulty index:

- Before and after project-based learning was implemented for students in session 2016/2017.

- Between students from session 2015/2016 who did not participate in project-based learning and students in session 2016/2017.

ii) Measuring the passing rate/failure rate between students from sessions 2016/2017 and 2015/2016 and thereby measuring the correlation i.e. whether there is a relationship between the performance in final exams with a project. This measurement was carried out using Pearson's product-moment correlation coefficient.

There are six Course Outcomes (COs) for this course. $\mathrm{CO} 1$ is the most important element in which students should understand the basics of the surface in spaces such as a sphere, ellipsoid, paraboloid, hyperboloid and others. $\mathrm{CO} 2$ and $\mathrm{CO} 3$ focus on partial derivatives and their applications while $\mathrm{CO} 4$ and $\mathrm{CO} 5$ cover the topics of integration and their applications. CO6 is the final outcome and is an introduction to the differentiation and integration of complex functions. Table 1 shows the Course Outcome matrix for this subject. 
Table 1. Course outcome for Vector Calculus course.

\begin{tabular}{|l|l|}
\hline Course Outcome & Description \\
\hline $\mathrm{CO} 1$ & Understand the basics of surfaces in space \\
\hline $\mathrm{CO} 2$ & Able to apply the basic concepts of partial derivatives \\
\hline $\mathrm{CO} 3$ & Understand and able to apply the concepts of vector function, vector field, scalar field, gradient, divergence and curl. \\
\hline $\mathrm{CO} 4$ & Able to apply the concepts of line integral, double integral and triple integral in solving engineering problems. \\
\hline $\mathrm{CO} 5$ & Able to apply Green's Theorem, Stokes' Theorem, and Gauss' Theorem in solving engineering problems. \\
\hline $\mathrm{CO} 6$ & Understand basic concepts of differentiation and integration of complex functions. \\
\hline
\end{tabular}

Table 2. Teaching plan with course outcome for each topic.

\begin{tabular}{|l|l|l|}
\hline Week & Topic & Course Outcome \\
\hline 1 & Surfaces in Space. & CO1 \\
\hline 2 & Vector functions. & CO1 \\
\hline 3 & Motion on a curve. Curvature and components of acceleration. & CO2 \\
\hline 4 & Partial derivatives. Directional derivatives... & CO2 \\
\hline 5 & Tangent planes and normal lines. Divergence and curl. & CO3 \\
\hline 6 & Line integrals. Independence of path. & CO4 \\
\hline 7 & Double integrals. Double integrals in polar coordinates. & CO4 \\
\hline 8 & Green's theorem. Surface integrals. & CO5 \\
\hline 9 & Stokes' theorem. & CO5 \\
\hline 10 & Triple integrals. & CO4 \\
\hline 11 & Gauss' theorem. Change of variables in multiple integrals. & CO5 \\
\hline 12 & Sets in the complex plane. Functions of a complex variable & CO6 \\
\hline 13 & Differentiation of complex functions. & CO6 \\
\hline 14 & Integration of complex functions. & CO6 \\
\hline
\end{tabular}

The lesson plans for each topic along with the Learning Outcomes are mapped in Table 2. Project-based learning is conducted after the mid-semester exam and covers topics 1 to 11 . Students are initially required to construct models using the equations for surfaces in space. The model then becomes the basis for understanding the next topics such as determining the curvature of the model, calculating the volume of the built model by using integration, determining the equations for the tangent and normal planes to the model and justifying the theorems learned. The student then presents the project that was implemented in the revision week (week 15).

For both sessions, there are three questions that cover $\mathrm{CO} 1$ and $\mathrm{CO} 2$ in the mid-semester exam questions. The final exam questions are made up of Parts A and B and consist of CO1 until CO6 as in Table 3 and Table 4. In terms of assessment division, the 2015/2016 session includes $15 \%$ quizzes, $5 \%$ e-learning, $10 \%$ cooperative learning, 20\% mid-semester exams and 50\% final semester exams. For the 2016/2017 session, assessments for the mid and final exams are the same as the previous session except quizzes and cooperative learning with $10 \%$ each, as well as project and e-learning with 5\% each.

Table 3. Mid-semester and final exam questions and the course outcome for Vector Calculus session 2015/2016

\begin{tabular}{|c|c|c|c|c|c|c|c|}
\hline \multirow{2}{*}{ Part } & $\begin{array}{c}\text { Question } \\
\text { No. }\end{array}$ & \multicolumn{7}{|c|}{ Course outcome (CO) } \\
\hline & CO1 & CO2 & CO3 & CO4 & CO5 & CO6 \\
\hline \multirow{5}{*}{ Mid-Sem } & Q1 & $\mathrm{X}$ & & & & & \\
\hline & Q2 & & $\mathrm{X}$ & & & & \\
\hline & Q3 & & $\mathrm{X}$ & & & & \\
\hline \multirow{5}{*}{$\begin{array}{c}\text { Final } \\
\text { Semester }\end{array}$} & Part A: Q1 & $\mathrm{X}$ & & & & & \\
\hline & Part A: Q2 & & & $\mathrm{X}$ & & & \\
\hline & Part A: Q3 & & $\mathrm{X}$ & & & & \\
\hline & Part A: Q4 & & & $\mathrm{X}$ & & & \\
\hline & Part A: Q5 & & & & $\mathrm{X}$ & & \\
\hline & Part A: Q6 & & & & & & $\mathrm{X}$ \\
\hline & Part B: Q1 & & & & $\mathrm{X}$ & & \\
\hline & Part B:Q2 & & & & & $\mathrm{X}$ & \\
\hline & Part B: Q3 & & & $\mathrm{X}$ & & & \\
\hline & Part B: Q4 & & & & & $\mathrm{X}$ & \\
\hline
\end{tabular}


Table 4. Mid-semester and final exam questions and the course outcome for Vector Calculus session 2016/2017

\begin{tabular}{|c|c|c|c|c|c|c|c|}
\hline \multirow{2}{*}{ Part } & Question & \multicolumn{6}{|c|}{ Course Outcome (CO) } \\
\hline & No. & $\mathrm{CO} 1$ & $\mathrm{CO} 2$ & $\mathrm{CO} 3$ & $\mathrm{CO} 4$ & $\mathrm{CO} 5$ & $\mathrm{CO}$ \\
\hline \multirow{4}{*}{ Mid-Sem } & $\mathrm{Q} 1$ & $\mathrm{X}$ & & & & & \\
\hline & $\mathrm{Q} 2$ & & $\mathrm{X}$ & & & & \\
\hline & $\mathrm{Q} 3$ & & $\mathrm{X}$ & & & & \\
\hline \multirow{5}{*}{$\begin{array}{c}\text { Final } \\
\text { Semester }\end{array}$} & Part A: Q1 & $\mathrm{X}$ & & & & & \\
\hline & Part A: Q2 & & & $\mathrm{X}$ & & & \\
\hline & Part A: Q3 & & & & $\mathrm{X}$ & & \\
\hline & Part A: Q4 & & & & $\mathrm{X}$ & & $\mathrm{X}$ \\
\hline & Part A: Q5 & & & & & & \\
\hline & Part B: Q1 & & $\mathrm{X}$ & & & & \\
\hline & Part B:Q2 & & & & $\mathrm{X}$ & & \\
\hline & Part B: Q3 & & & & & $\mathrm{X}$ & \\
\hline
\end{tabular}

\subsection{Difficulty Index}

Table 5. Classification of difficulty indices

\begin{tabular}{|c|}
\hline 1 \\
0.9 \\
0.8 \\
0.7 \\
0.6 \\
0.5 \\
0.4 \\
0.3 \\
0.2 \\
0.1 \\
0 \\
\hline
\end{tabular}
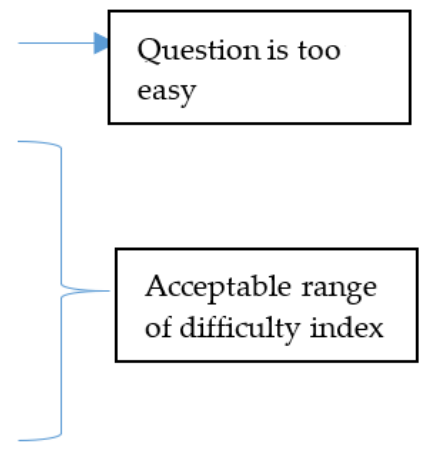

Question is too hard

The difficulty index is an instrument used to test the difficulty level of a question. The level can be categorised as easy, moderate and difficult (Chatterjee et al., 2020) and is shown in Table 5. Good questions are at moderate levels ranging from 0.3 to 0.8 . Moderate questions can determine whether the Learning Outcomes are achieved or not. Difficult questions with index values approaching 0 can be used to determine high-achieving and outstanding students. The formula for calculating the difficulty index is as follows:

$$
\text { Difficulty Index } \operatorname{question~}(i)=\frac{M_{T(i)}+M_{R(i)}}{N * m_{i}}
$$

where

$M_{T(i)}=$ total marks of high students performance group

$M_{R(i)}=$ total marks of low students performance group

$N=$ total number of student for both groups

$m_{i}=$ total marks for question $i$

where

\subsection{Pearson Product-Moment Correlation Coefficient Test}

For Pearson's product correlation coefficient, $r$ test is used to examine, measure and visualise the existence and strength relationship between two continuous variable data i.e. in this case the scores of projects obtained with the final exam scores and also between the marks of the mid-semester exams and final exam scores.

If all the assumptions are met, the Pearson product moment correlation coefficient, $r$ can be found by using two hypotheses:

$\mathrm{H}_{0}$ : No linear relationship between the project scores results and the final exam results

$\mathrm{H}_{1}$ : There is a linear relationship between the project scores results with the final exam results and,

$\mathrm{H}_{0}$ : There is no linear relationship between the results of the mid-semester exam with the results of the final exam

$\mathrm{H}_{1}$ : There is a linear relationship between the results of the mid-semester exam with the results of the final exam

\section{Results and Discussion}

Figure 1 shows the difficulty index value for each $\mathrm{CO}$ calculated for students from the 2016/2017 session. The comparison is done between the mid and final exam results. The average value of the difficulty index is calculated for questions with the same $\mathrm{CO}$. The index value before the project was implemented is taken based on the mid-semester exam score while the index value after the project was done is calculated based on the final exam score. Only the difficulty index from two COs is taken since they are both tested in mid and final exam questions. Based on the figure, it can be seen that the index values for final exam questions (0.587 and 0.509) are bigger and lie at the top of the graph compared to the index values for the mid-semester exam (0.512 and 0.466). This result indicates that the students found it easier to answer final exam questions compared to mid-semester exam questions. 


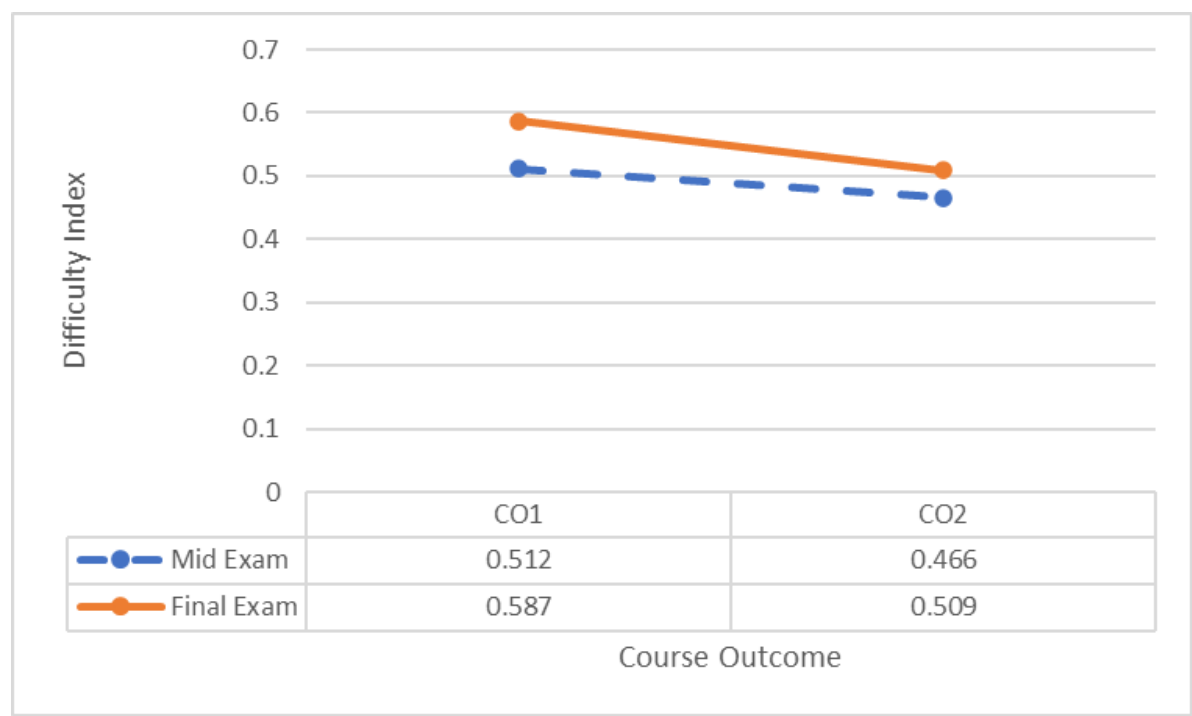

Figure 1. Difficulty index for mid and final exam paper session 2016/2017

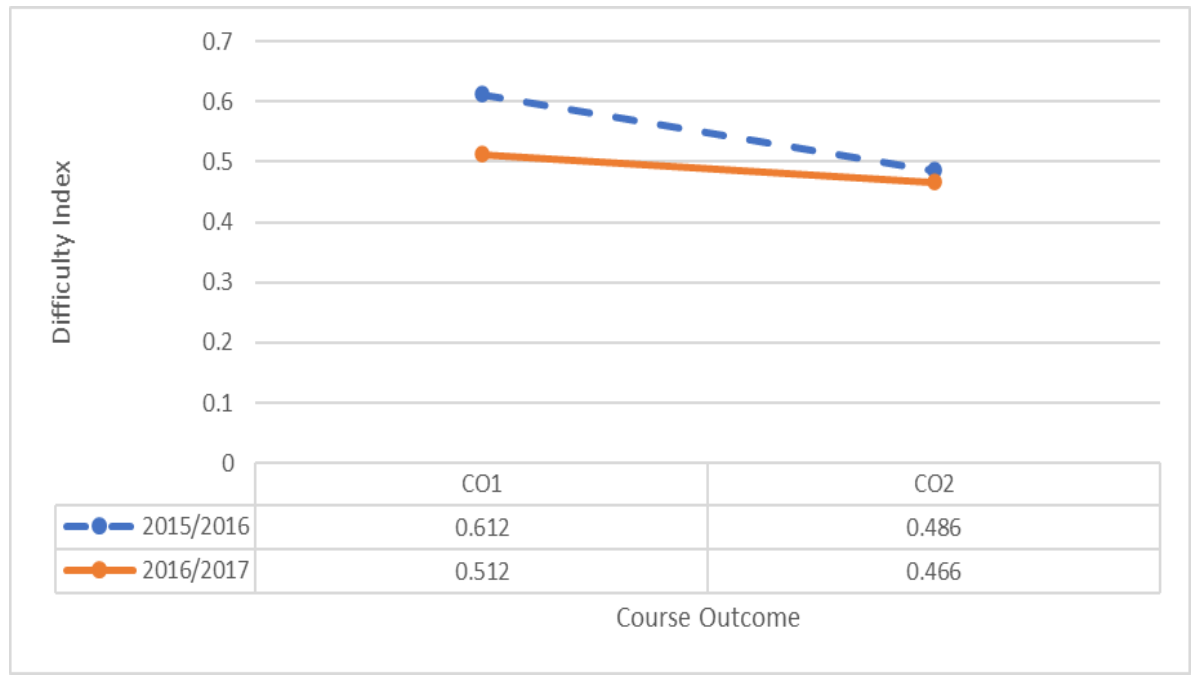

Figure 2. Difficulty index for mid-semester exam paper for 2015/2016 and 2016/2017 sessions

Figure 2 shows a comparison of the difficulty index values based on the mid-semester exam score between the students from 2015/2016 who did not perform the project-based learning and students from the 2016/2017 session. It can be seen that all questions that include $\mathrm{CO} 1$ and $\mathrm{CO} 2$ are in the good range between 0.4-0.7. In terms of students' ability to answer, it is observed that students from the 2015/2016 session feel that these questions are easier to answer than students from the 2016/2017 session. This can be seen based on the position of the graph that lies above and approaching the index value of 1 .

In Figure 3, the difficulty index value is compared between students from both sessions based on the result from the final exams. The final exam questions are in a moderate range between $0.3-0.6$. In this figure, different trends can be seen where the index values for the 2016/2017 session are greater than the index values for the 2015/2016 session for most COs. The 2016/2017 students feel that the $\mathrm{CO} 1, \mathrm{CO} 3, \mathrm{CO} 4, \mathrm{CO} 5$ and $\mathrm{CO} 6$ questions are easier to answer than the students from previous session, with the exception of the $\mathrm{CO} 2$ questions. This can be seen based on the difficulty index graph that lies at the top for session 2016/2017 in all COs except CO2. 


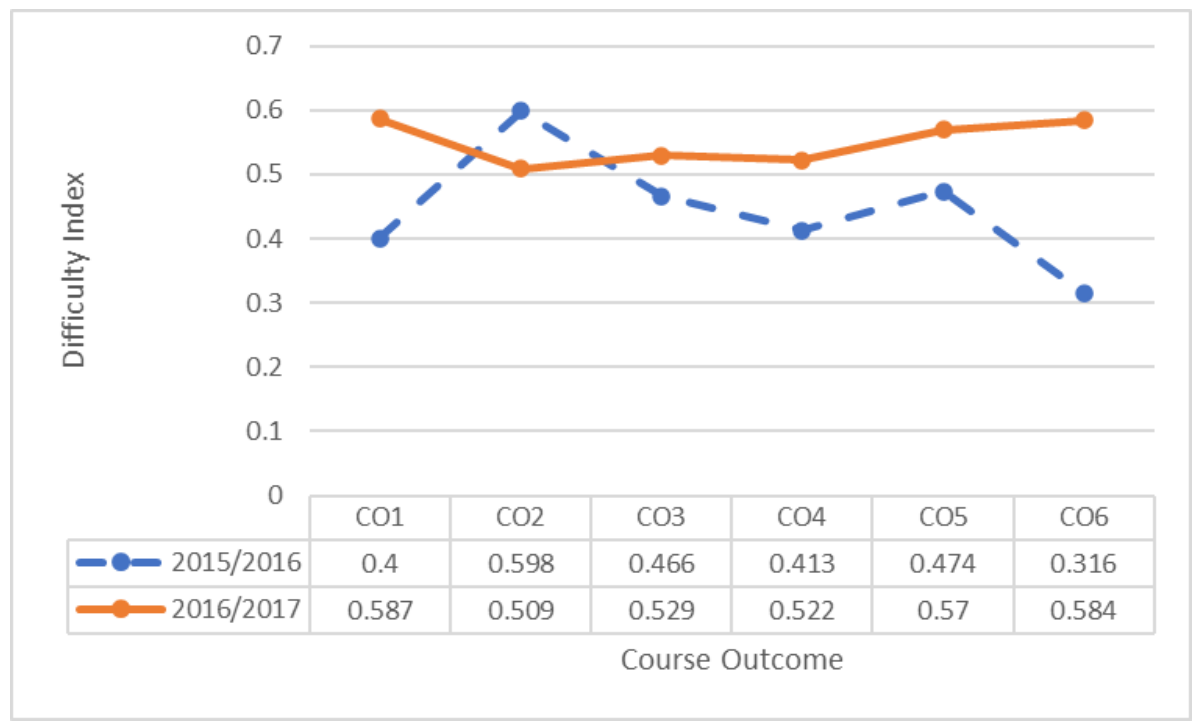

Figure 3. Difficulty index for final exam paper for 2015/2016 and 2016/2017 sessions

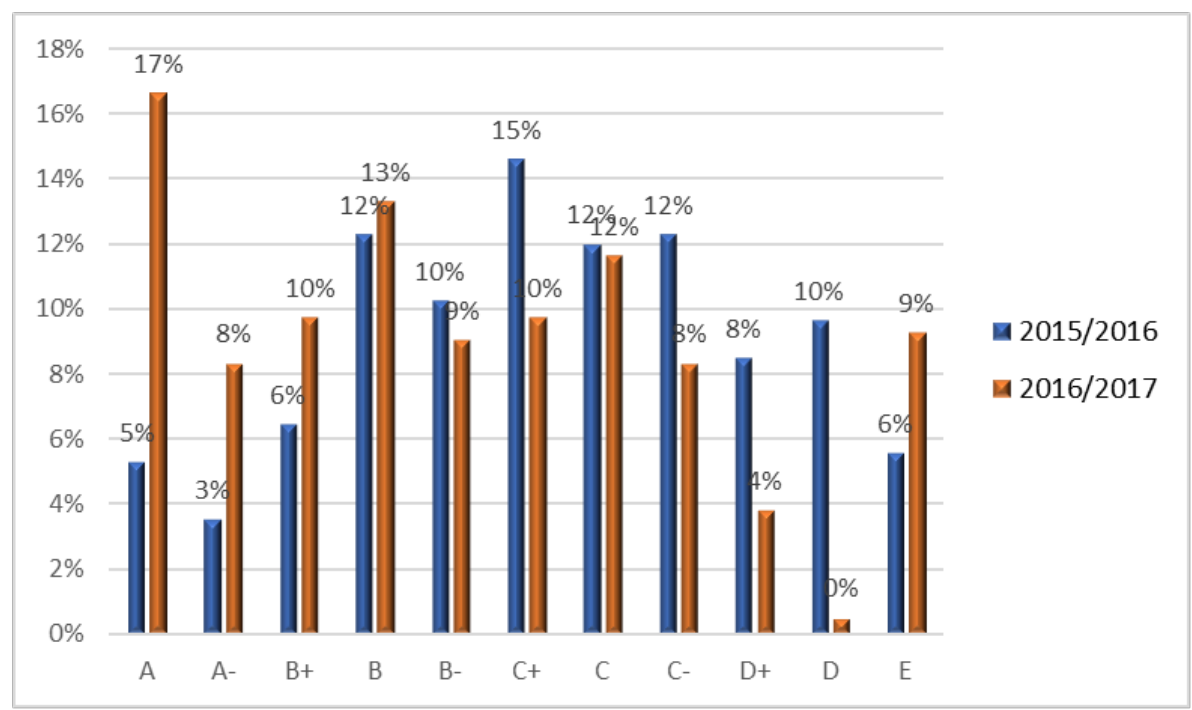

Figure 4. Percentage of students with each grade for $2015 / 2016$ and 2016/2017 sessions

In Figure 4, we present the overall percentage including continuous assessments for both sessions. It is observed that the overall percentage of students with good grades increased for the 2016/2017 session compared to the $2015 / 2016$ session especially for A where $17 \%$ of students obtained this grade in the 2016/2017 session compared to 5\% in the previous year. Likewise, for grades $\mathrm{A}-, \mathrm{B}+$ and $\mathrm{B}$, where each grade recorded an increase of $5 \%, 4 \%$, and $1 \%$, respectively. The percentages of students with poor grades from B to D are lower in the 2016/2017 session compared to the previous session. Grade D recorded a significant drop where $0 \%$ of the $2016 / 2017$ session students gained this grade compared to $10 \%$ in the previous session. However, the percentage of students earning $\mathrm{E}$ for the
$2016 / 2017$ session slightly increased to $9 \%$ compared to $6 \%$ from the previous session.

In terms of the correlation between the final score and project-based learning score, it can be seen that the relation is weak (Pearson's 0.123 correlation) and indicates that the linear assumptions are not met. This means that the project scores do not have a big impact on the final score with an $r^{2}$ value of only $1.5 \%$ of project score contributing to the final exam scores. The correlation of the final and mid-semester scores is however moderately positive with a value of 0.658 and $43.2 \%$ of the final score contributed by the results of the mid-semester exam results. This can be seen in Figures 5 and 6 and summarised in Table 6. 


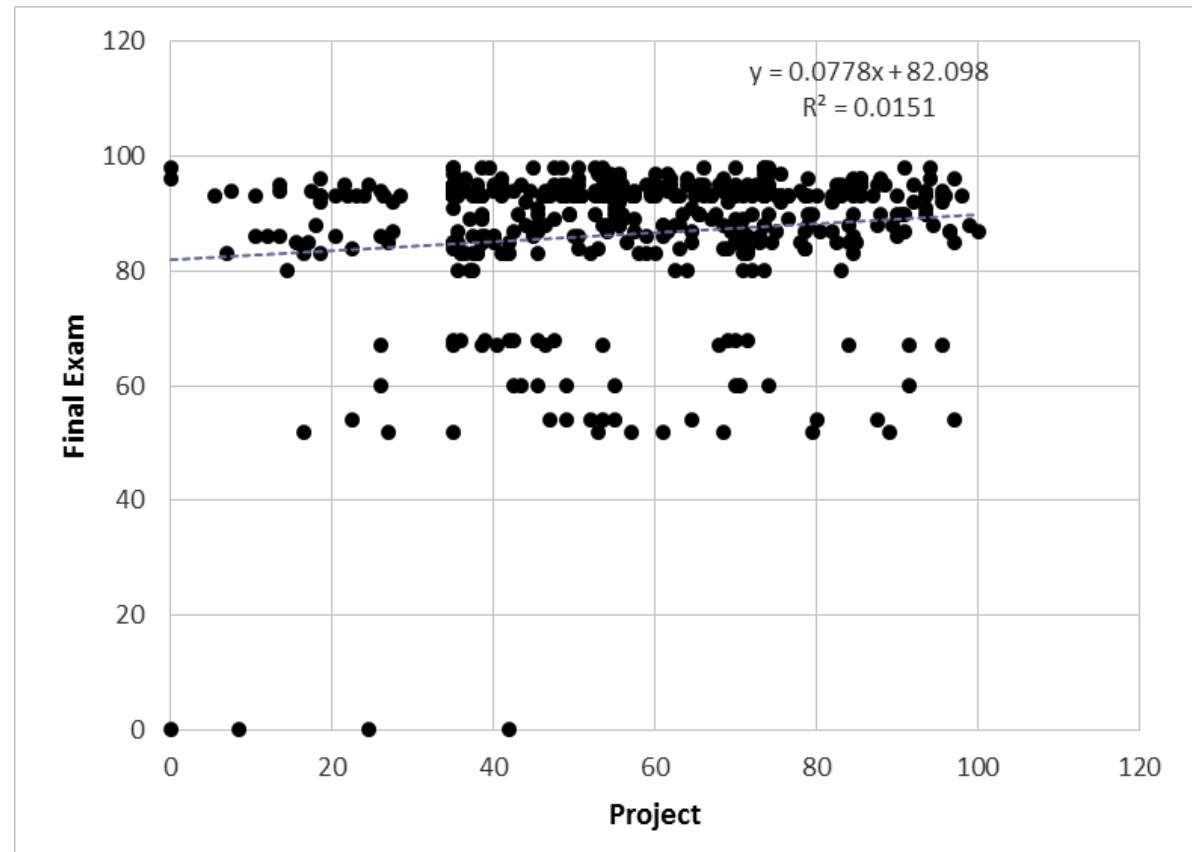

Figure 5. Relation between project and final exam scores for $2016 / 2017$ session

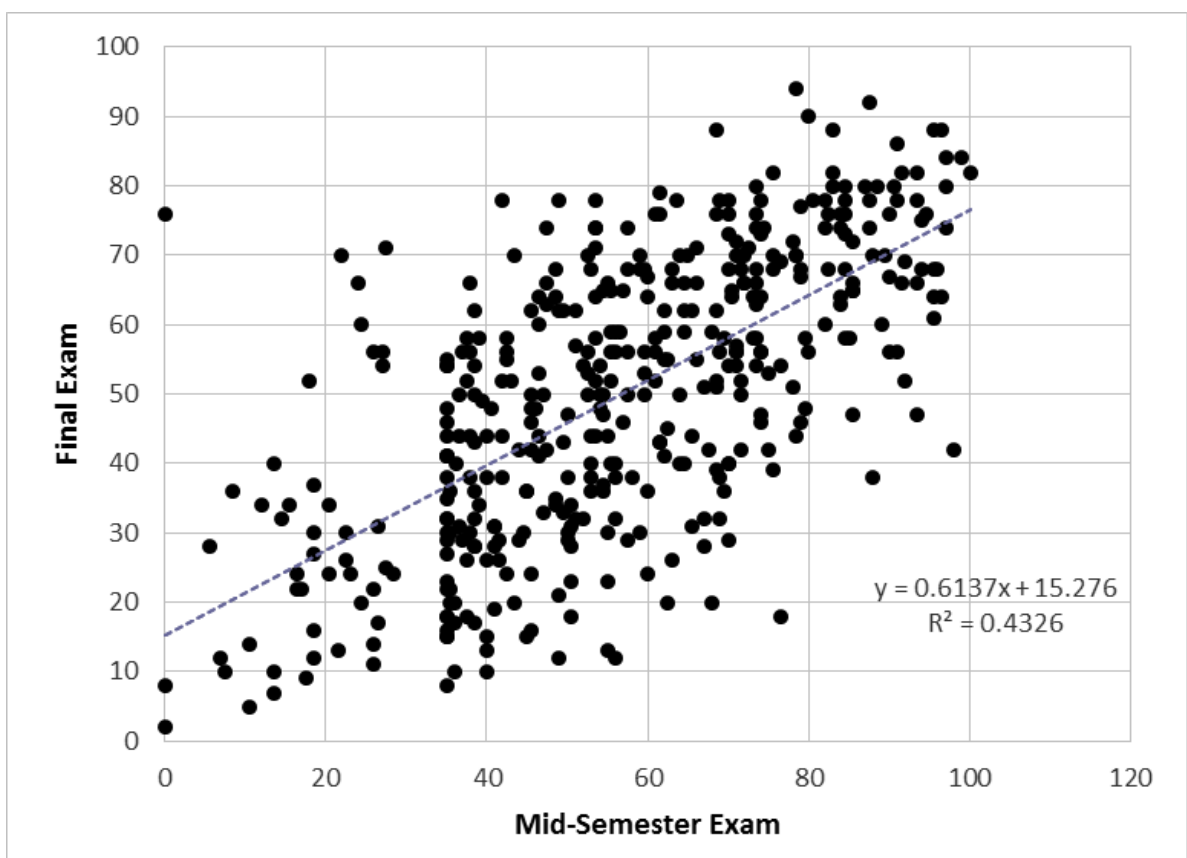

Figure 6. Relation between mid and final exam scores for 2016/2017 session

Table 6. Pearson's product-moment correlation coefficient

\begin{tabular}{|c|c|c|c|c|}
\hline Courses & $\mathbf{N}$ & Pearson Correlation, $\boldsymbol{r}$ & Sig. (p-value) & $\mathbf{R}^{\mathbf{2}}$ \\
\hline Final - Project & 422 & 0.123 & 0.000 & 0.0151 \\
\hline Final - Mid & 422 & 0.658 & 0.000 & 0.4326 \\
\hline
\end{tabular}




\section{Conclusions}

Based on the results of this study, we can conclude that the students have achieved all the course outcomes based on the result of the difficulty index that lies in the acceptable range. The performance of students implementing project-based learning is better after using this method in teaching and learning sessions. This can be clearly seen based on the difficulty index value before and after the project was implemented. Comparisons were also made among students in the previous session. The effect sizes indicate that on average examination scores improved by about $12 \%$ with project-based learning and students in classes with project-based learning were 3.4 times more likely to get As than students in classes without project-based learning. Although the comparisons were made between two different sets of students and have different backgrounds, the results give some positive feedback on the improvements that have been made. The number of teaching staffs for both sessions is the same. However, project-based learning is student-centric (active learning) and therefore the role of the teachers are as a facilitator when compared to the previous session where there is no project-based learning and the role of teacher is to give lecture (passive learning). The findings show that students in the 2016/2017 session were able to master the project-based learning related questions better than previous students. The increase in the percentage of students getting A grades in the 2016/2017 session is large, but project-based learning scores are seen as not the major contributors to the overall scores. Suggestions for raising the percentage of project scores are encouraged to increase the impact on overall scores, thereby enhancing student performance and reducing the percentage of student failures.

\section{Acknowledgments}

The authors would like to thank the Ministry of Higher Education Malaysia and Universiti Kebangsaan Malaysia for their support under the grant code GUP-2019-025.

\section{REFERENCES}

[1] Benware, C.A. \& Deci, E.L. (1984). Quality of learning with an active versus passive motivational set. American Educational Research Journal, 21, 4. 755-765.

[2] Bybee, R.W. (2010). Advancing STEM education: A 2020 vision. Technology and Engineering Teacher, 70, 1. 30-35.

[3] Carlson, L.E. \& Sullivan, J.F. (1999). Hands-on engineering: Learning by doing in the integrated teaching and learning program. International Journal of Engineering Education, $15,1.20-31$.
[4] Chatterjee, D., Jha, S. K., \& Maiti, S. (2020). Development of Knowledge Test Regarding Method of Preparation of Traditional Dairy Products. Indian Research Journal of Extension Education, 20(1), 9-14.

[5] De La Harpe, B., Radloff, A. \& Wyber, J. (2000). Quality and generic (professional) skills. Quality in Higher Education, 6, 3. 231-243.

[6] Deutsch, M. (2020). Speaker's reference, stipulation, and a dilemma for conceptual engineers. Philosophical Studies, $1-23$.

[7] Han, S., Capraro, R. \& Capraro, M.M. (2015). How science, technology, engineering, and mathematics (stem) project-based learning (PBL) affects high, middle, and low achievers differently: the impact of student factors on achievement. International Journal of Science and Mathematics Education, 13, 5. 1089-1113.

[8] Krajcik, J.S. \& Blumenfeld, P.C. (2006). Project-based learning. The Cambridge Handbook of the Learning Sciences (1-19)-. Cambridge University Press.

[9] Lalley, J. \& Miller, R. (2007). The learning pyramid: Does it point teachers in the right direction. Education, 128, 1. 16.

[10] Li, P. L., Ko, A. J., \& Begel, A. (2020). What distinguishes great software engineers? Empirical Software Engineering, 25(1), 322-352.

[11] Male, S.A. (2010). Generic engineering competencies: A review and modelling approach. Education Research and Perspectives, 37, 1. 25.

[12] Mills, J.E. \& Treagust, D.F. (2003). Engineering education Is problem-based or project based learning the answer. Australasian Journal of Engineering Education, 3, 2. 2-16.

[13] Othman, H., Asshaari, I., Tawil, N. M., Ismail, N. A., Nopiah, Z. M., \& Zaharim, A. (2012). Analysis on Mathematics Fundamental Knowledge for Mathematics Engineering Courses based on a Comparative Study of Students' Entry Performance. Procedia-Social and Behavioral Sciences, 60, 365-371.

[14] Rate, R. (2005). Learning pyramid.

[15] Saad, A. (2020). Students' Computational Thinking Skill through Cooperative Learning Based on Hands-on, Inquiry-based, and Student-centric Learning Approaches. Universal Journal of Educational Research, 8(1), 290-296.

[16] Tang, H. E., Voon, L. L., \& Julaihi, N. H. (2009, March). A Case Study of 'High-Failure Rate' Mathematics Courses and its Contributing Factors on UiTM Sarawak Diploma Students. In Conference on Scientific and Social Research (pp. 14-15).

[17] Wood, E.J. (2004). Problem-based learning: Exploiting knowledge of how people learn to promote effective learning. Bioscience Education, 3, 1. 1-12.

[18] Wurdinger, S., Newell, R., \& Kim, E. S. (2020). Measuring life skills, hope, and academic growth at project-based learning schools. Improving Schools, 1365480220901968. 